\title{
High-Efficiency Supercapacitor Charger Using an Improved Two-Switch Forward Converter
}

\author{
Woo-Young Choi ${ }^{\dagger}$, Min-Kwon Yang ${ }^{*}$, and Yongsug Suh ${ }^{* *}$ \\ $\dot{\dagger}^{*}$ Division of Electronic Engineering, Chonbuk National University, Jeonju, Korea \\ ${ }^{* *}$ Department of Electrical Engineering, Chonbuk National University, Jeonju, Korea
}

\begin{abstract}
This paper proposes a high-efficiency supercapacitor charger. Conventional two-switch forward converter can be used for charging supercapacitors. However, the efficiency of conventional converters is low because of their switching losses. This study presents a high-efficiency two-switch forward converter for supercapacitor chargers. The proposed converter improves power efficiency by $4 \%$, from $89 \%$ to $93 \%$. The proposed converter has the advantages of reduced switch voltage stresses and minimized circulating current when compared to other converter topologies. The performance of the proposed converter is evaluated by experimental results using a $300 \mathrm{~W}$ prototype circuit for a 54-V, 35-F supercapacitor bank.
\end{abstract}

Key words: Forward converter, High-efficiency, Supercapacitor charger, Switching loss

\section{INTRODUCTION}

Supercapacitors have been widely used for automotive and energy conversion systems [1]-[3]. The life and capacity of supercapacitors depend on several factors such as charge mode, maintenance, temperature, and age [4]. Among these factors, the charge mode has the greatest impact on battery life and capacity. Supercapacitors are charged with current and voltage levels by a supercapacitor charger [5]. The supercapacitor charger is designed by using switched mode power supplies. The basic requirements for supercapacitor chargers are small size and high efficiency. A high switching frequency is necessary to achieve a small size. However, as the switching frequency is increased, the efficiency of the supercapacitor chargers is reduced because the switching losses increase. Thus, selecting an optimal converter topology is important for the design of high-efficiency supercapacitor chargers.

The forward converter is a popular DC-DC converter topology for low voltage and high current applications [6], [7]. In particular, the two-switch forward converter in Fig. 1 is a good candidate for supercapacitor chargers due to its simple structure and low switch voltage stress [8]-[11]. The two switches $S_{1}$ and $S_{2}$ are turned on and off simultaneously [10].

Manuscript received Jun. 20, 2013; revised Oct. 4, 2013

Recommended for publication by Associate Editor Yong Kang.

${ }^{\dagger}$ Corresponding Author: wychoi@jbnu.ac.kr

Tel: +82-63-270-2409, Fax: +82-63-270-2394, Chonbuk Nat'l University

*Department of Electronic Eng., Chonbuk National University, Korea

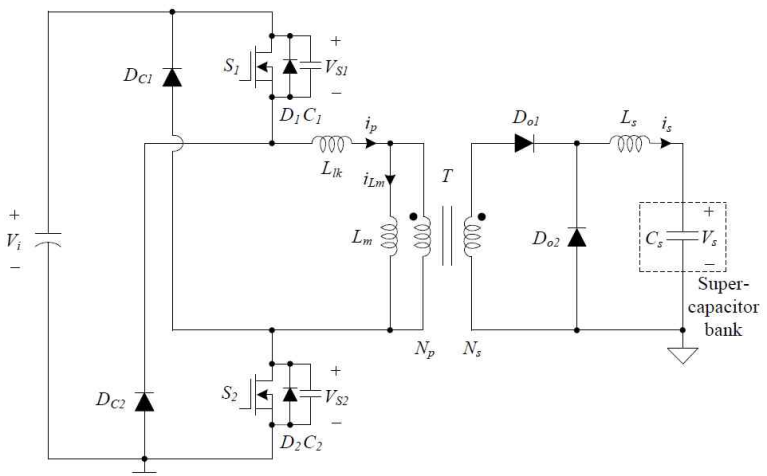

Fig. 1. Circuit diagram of the conventional two-switch forward converter.

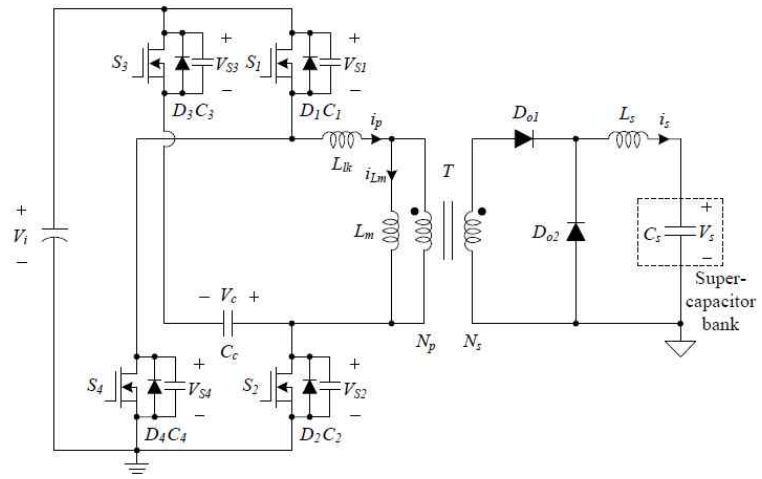

Fig. 2. Circuit diagram of the proposed two-switch forward converter. 


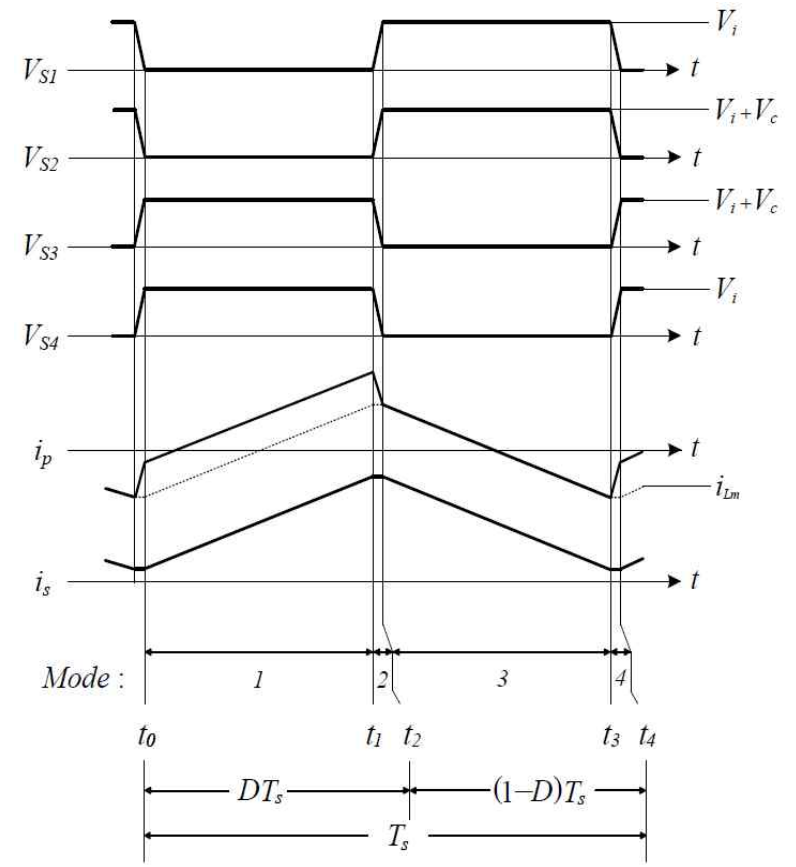

Fig. 3. Switching waveforms of the proposed converter.

The magnetizing current $i_{L m}$ flows into the input source $V_{i}$ through the reset diodes $D_{C l}$ and $D_{C 2}$. Thus, the two-switch forward converter can eliminate the need for a separate demagnetizing winding, which is used in the conventional forward converter. However, when the switches are turned off, the energy stored in the leakage inductor $L_{l k}$ causes high voltage spikes across the switches [11]. These voltage spikes increase the switching losses. Another drawback of the two-switch forward converter is a duty cycle limitation [12]. The maximum duty cycle is limited to 0.5 to guarantee the transformer reset. This small duty cycle operation increases the output filter size and current stress. To cope with these problems, the active-clamping method has recently been applied to the two-switch forward converter [13], [14]. By using one more power switches in the primary side, zero-voltage switching of the power switches is achieved. However, the voltage stress of the auxiliary switch for the active-clamping circuit is still high. As a result, high-cost switches are usually used.

To relieve the abovementioned drawbacks, a high-efficiency two-switch forward converter is proposed for supercapacitor chargers. The proposed converter in Fig. 2 can reduce switching losses. The two reset diodes are replaced by two auxiliary switches $S_{3}$ and $S_{4}$. As a result, all of the power switches operate without any voltage spikes. Switching losses can be reduced by zero-voltage switching of the power switches. The duty cycle range is also extended by using one clamping capacitor $C_{c}$. Thus, the proposed converter can be used for a high input voltage range of around $300 \mathrm{~V} \sim 400 \mathrm{~V}$. In addition, the proposed converter has the advantages of reduced switch voltage stresses and minimized circulating current when compared to the other converter topologies. The supercapacitor charging strategy is presented by using a constant current and constant voltage charging control [15]. All of the control functions are implemented in software with a single-chip microcontroller. The proposed converter is realized with minimal hardware at a low-cost. The performance of the proposed converter is evaluated through experimental results by using a $300 \mathrm{~W}$ prototype circuit for a $54-\mathrm{V}, 35-\mathrm{F}$ supercapacitor bank. The proposed converter improves the converter efficiency by $4 \%$, from $89 \%$ to $93 \%$.

\section{PROPOSED CONVERTER}

\section{A. Converter Operation}

Fig. 2 shows a circuit diagram of the proposed converter. $V_{i}$ is the input voltage. $V_{s}$ is the supercapacitor voltage. The primary part consists of power switches $\left(S_{1}, S_{2}, S_{3}, S_{4}\right)$, a clamping capacitor $\left(C_{c}\right)$, and a transformer $(T)$. The power switches are considered to be ideal switches except body diodes $D_{1} \sim D_{4}$ and output capacitors $C_{1} \sim C_{4}$. The transformer $T$ has a magnetizing inductor $L_{m}$ and leakage inductor $L_{l k}$ with a turns ratio of $1: N$ where $N=N_{s} / N_{p}$. The secondary part consists of output diodes $\left(D_{o l}, D_{o 2}\right)$, an output filter inductor $\left(L_{s}\right)$, and a supercapacitor bank $\left(C_{s}\right)$.

Fig. 3 shows the switching waveforms of the proposed converter during one switching period $T_{s}$. The converter has four switching modes during $T_{s}$. $S_{1}$ and $S_{2}$ are turned on and off simultaneously. $S_{3}$ and $S_{4}$ are also turned on and off simultaneously. Then, $S_{I} \quad\left(S_{2}\right)$ and $S_{3} \quad\left(S_{4}\right)$ operate complementarily with a short dead time. When the duty cycle $D$ is based on the on-time of $S_{1}$ and $S_{2}$, the duty cycle of $S_{3}$ and $S_{4}$ is $1-D$. Before $t=t_{0}, S_{3}$ and $S_{4}$ are turned off. Voltages $V_{S I}$ and $V_{S 2}$ are zero when the primary current $i_{p}$ flows through body diodes $D_{1}$ and $D_{2}$.

Mode $1\left[t_{0}, t_{L}\right]$ : At $t=t_{0}, S_{1}$ and $S_{2}$ are turned on at zero voltage. $L_{m}$ and $L_{l k}$ store energy from $V_{i}$. The magnetizing inductor current $i_{L m}$ increases linearly as

$$
i_{L m}(t)=i_{L m}\left(t_{0}\right)+\frac{V_{i}}{L_{m}+L_{l k}}\left(t-t_{0}\right) .
$$

At the secondary side, output diode $D_{o l}$ is turned on. The output inductor current $i_{s}$ flows through output diode $D_{o 1}$.

Mode $2\left[t_{1}, t_{2}\right]$ : At $t=t_{1}, S_{1}$ and $S_{2}$ are turned off. The primary current $i_{p}$ charges $C_{1}$ and $C_{2}$ and discharges $C_{3}$ and $C_{4}$. $V_{S I}$ increases from zero to $V_{i}$ while $V_{S 2}$ increases from zero to $V_{i}$ $+V_{c}$. $V_{S 3}$ decreases from $V_{i}+V_{c}$ to zero while $V_{S 4}$ decreases from $V_{i}$ to zero. Since the switch output capacitor $C_{s}\left(=C_{I}=C_{2}\right.$ $=C_{3}=C_{4}$ ) is very small, the time interval during this mode is considered negligible when compared to $T_{s}$. The magnetizing current $i_{L m}$ is considered to be constant. Switch body diodes $D_{3}$ and $D_{4}$ conduct the primary current $i_{p}$ at the end of this mode.

Mode $3\left[t_{2}, t_{3}\right]$ : At $t=t_{2}, S_{3}$ and $S_{4}$ are turned on at zero voltage. The energy stored in $L_{l k}$ is recycled to the clamping 


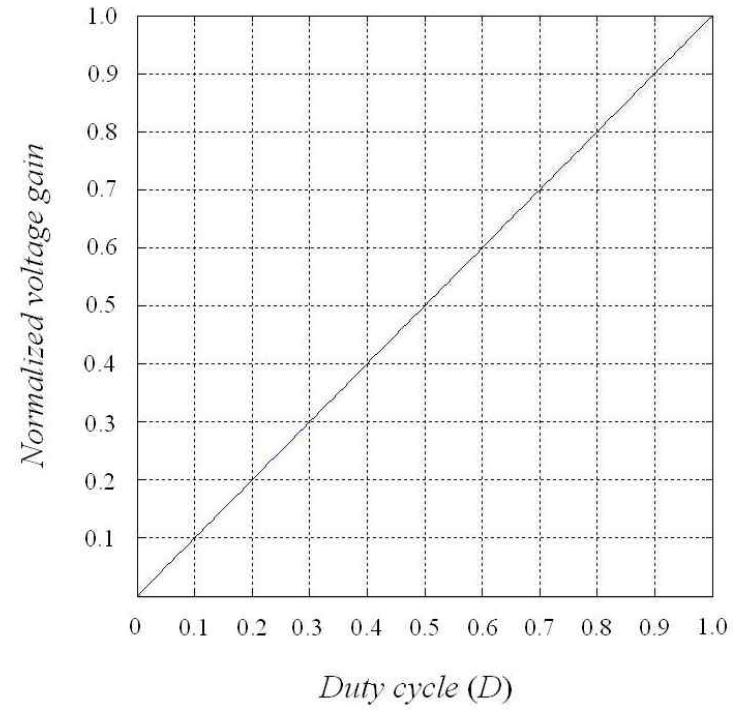

Fig. 4. Graph for the normalized voltage gain between the input voltage $V_{i}$ and supercapacitor voltage $V_{s}$.

capacitor $C_{c}$. $S_{3}$ and $S_{4}$ are turned on without any voltage spikes. The magnetizing inductor current $i_{L m}$ decreases linearly as:

$$
i_{L m}(t)=i_{L m}\left(t_{2}\right)-\frac{\left(V_{i}+V_{c}\right)}{L_{m}+L_{l k}}\left(t-t_{2}\right) .
$$

At the secondary side, output diode $D_{o 2}$ is turned on. The output inductor current $i_{s}$ freewheels through output diode $D_{o 2}$.

Mode $4\left[t_{3}, t_{4}\right]$ : At $t=t_{3}, S_{3}$ and $S_{4}$ are turned off. The primary current $i_{p}$ charges $C_{3}$ and $C_{4}$ and discharges $C_{1}$ and $C_{2}$. $V_{S 1}$ decreases from $V_{i}$ to zero while $V_{S 2}$ decreases from $V_{i}+V_{c}$ to zero. $V_{S 3}$ increases from zero to $V_{i}+V_{c}$ while $V_{S 4}$ increases from zero to $V_{i}$. Switch body diodes $D_{1}$ and $D_{2}$ conduct the primary current $i_{p}$. The next switching cycle begins when $S_{l}$ and $S_{2}$ are turned on at zero voltage again.

\section{B. Circuit Analysis}

The voltage stress of $S_{1}$ and $S_{4}$ is clamped to the input voltage $V_{i}$. The voltage stress of $S_{2}$ and $S_{3}$ is clamped to the sum of $V_{i}$ and $V_{c}$. For the volt-second balance relation on $L_{m}$ during $T_{s}$, the following relation between $V_{i}$ and $V_{c}$ is obtained as:

$$
V_{i} D T_{s}-\left(V_{i}+V_{c}\right)(1-D) T_{s}=0 .
$$

By rearranging (3), the clamp capacitor voltage $V_{c}$ is derived as:

$$
V_{c}=\frac{2 D-1}{1-D} V_{i} .
$$

For the volt-second balance relation on $L_{s}$ during $T_{s}$, the following relation between $V_{i}$ and $V_{s}$ is obtained as:

$$
\frac{V_{s}}{V_{i}}=N D \text {. }
$$

Fig. 4 shows a graph of the normalized voltage gain between $V_{i}$ and $V_{s}$. As the duty cycle $D$ varies from zero to one, the normalized voltage gain increases linearly. When compared to the duty cycle of the previous two-switch forward converter [10], the proposed converter has a wide duty cycle range from zero to one. In particular, when the duty cycle $D$ is below 0.5 , the clamping capacitor voltage $V_{c}$ can be lower than the input voltage $V_{i}$.

\section{Zero-Voltage Switching Conditions}

In order to achieve zero-voltage switching of $S_{3}$ and $S_{4}$, the energy stored in $L_{m}$ and $L_{s}$ should be larger than the energy stored in the switch output capacitors, as suggested in [16]. The zero-voltage switching condition of $S_{3}$ and $S_{4}$ is:

$$
\frac{L_{m} i_{L m}^{2}\left(t_{2}\right)}{2}+\frac{L_{s} i_{D o 1}^{2}\left(t_{2}\right)}{2}>\frac{\left(C_{1}+C_{4}\right)}{2} V_{i}^{2}+\frac{\left(C_{2}+C_{3}\right)}{2}\left(V_{i}+V_{c}\right)^{2} \text {. }
$$

Similarly, in order to achieve zero-voltage switching of $S_{I}$ and $S_{2}$, the energy stored in $L_{m}$ and $L_{s}$ should be larger than the energy stored in the switch output capacitors. The zero-voltage switching condition of $S_{1}$ and $S_{2}$ is:

$$
\frac{L_{m} i_{L m}^{2}\left(t_{4}\right)}{2}+\frac{L_{s} i_{D o 2}^{2}\left(t_{4}\right)}{2}>\frac{\left(C_{1}+C_{4}\right)}{2} V_{i}^{2}+\frac{\left(C_{2}+C_{3}\right)}{2}\left(V_{i}+V_{c}\right)^{2} \text {. }
$$

\section{Voltage and Current Stresses}

In the proposed converter, the voltage stress of $S_{1}$ and $S_{4}$ is clamped to the input voltage. On the other hand, the voltage stress of $S_{2}$ and $S_{3}$ is the sum of the input voltage and the clamping capacitor voltage. The voltage stress of $S_{2}$ and $S_{3}$ can be changed with the duty ratio $D$. When the duty cycle $D$ is below 0.5 , the voltage stress of $S_{2}$ and $S_{3}$ can be lower than the input voltage $V_{i}$. This is one of the advantages of the proposed converter when compared to the other full-bridge (FB) converter topologies. Table I summarizes the voltage and current stresses of the proposed converter.

\section{E. Circulating Current}

In the phase-shifted full-bridge (PSFB) converter [17], a circulating current is inevitable during the freewheeling period. It is especially large at a high input voltage, causing the large conduction losses associated with the transformer and primary switches. This is because there exists a non-powering period, as shown in Fig. 5(a), where a zero voltage is applied to the transformer winding. The power is not delivered to the secondary side even though the current is circulating at the primary side. On the other hand, in the proposed converter, there is no freewheeling period except for a small dead-time period, as shown in Fig. 5(b). The power can always be delivered to the secondary side. There is no zero voltage period across the transformer winding. This is another advantage of the proposed converter when compared to the FB converter topologies. 


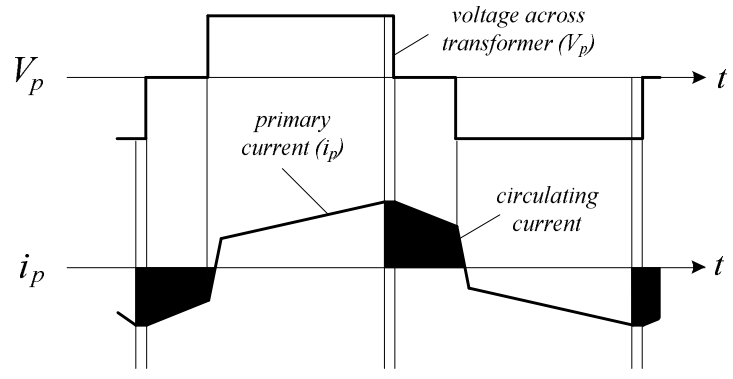

(a)

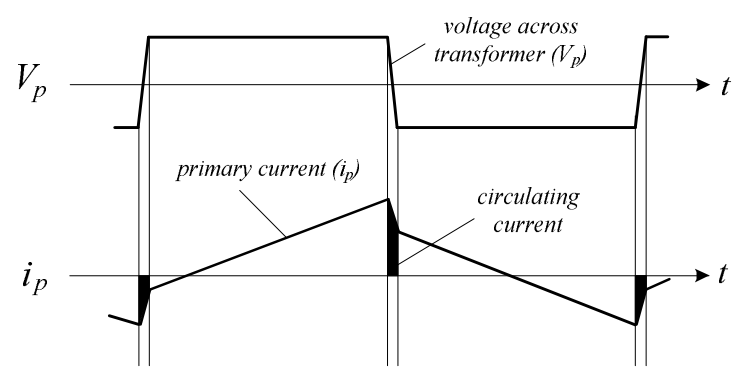

(b)

Fig. 5. Comparison of key waveforms between the PSFB converter and proposed converter: (a) PSFB converter and (b) proposed converter.

\section{TABLE I}

Voltage AND CURRENT Stresses of THE Rroposed CONVERTER

\begin{tabular}{|c|c|c|}
\hline Switch & Voltage Stress & Current Stress \\
\hline$S_{1}$ & $V_{i}$ & $N i_{o}+\frac{V_{i}}{2 L_{m}} D T_{s}$ \\
\hline$S_{2}$ & $V_{i}+V_{c}=\frac{D}{1-D} V_{i}$ & $N i_{o}+\frac{V_{i}}{2 L_{m}} D T_{s}$ \\
\hline$S_{3}$ & $V_{i}+V_{c}=\frac{D}{1-D} V_{i}$ & $N i_{o}-\frac{V_{i}+V_{c}}{2 L_{m}}(1-D) T_{s}$ \\
\hline$S_{4}$ & $V_{i}$ & $N i_{o}-\frac{V_{i}+V_{c}}{2 L_{m}}(1-D) T_{s}$ \\
\hline
\end{tabular}

\section{F. Averaged Model}

In the proposed converter, the switch power stage, together with the transformers and rectifier, can be substituted with an equivalent pulse source $V_{g}$, as illustrated in Fig. 6. This pulsating source can be averaged to a constant dc voltage source $V_{d}$. Assume that the output filter inductor current is in the continuous-conduction mode. The average model can then be derived as an equivalent buck converter topology, with an equivalent switching frequency. By using the state-space averaging method [18], the state-space averaged dc model is expressed as:

$$
0=A \cdot\left[\begin{array}{l}
I_{s} \\
V_{s}
\end{array}\right]+B \cdot V_{d}
$$

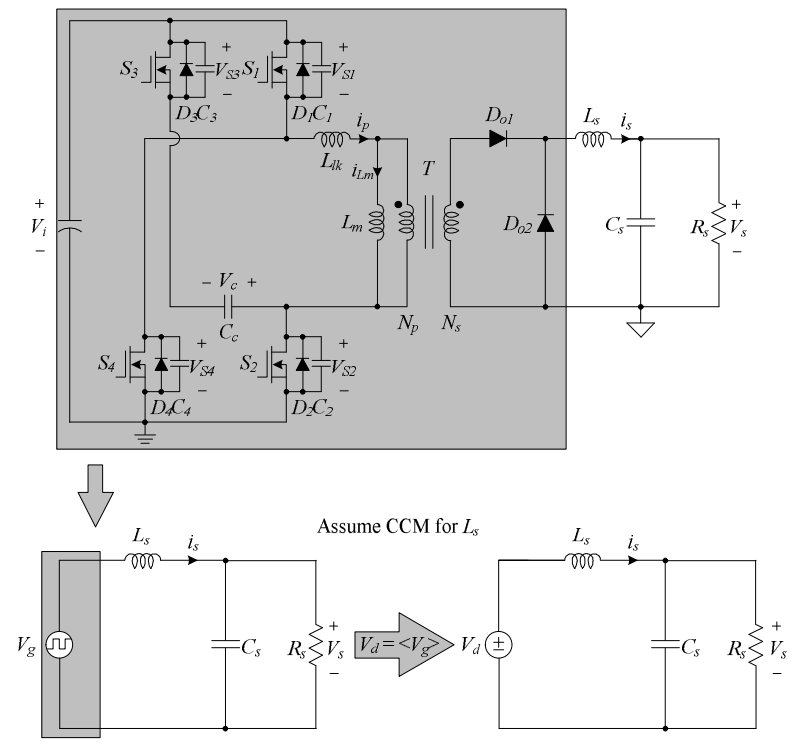

Fig. 6. Derivation of the average model.

where:

$$
A=\left[\begin{array}{cc}
0 & -\frac{1}{L_{s}} \\
\frac{1}{C_{s}} & -\frac{1}{C_{s} R_{s}}
\end{array}\right] \quad B=\left[\begin{array}{c}
\frac{D}{L_{s}} \\
0
\end{array}\right]
$$

where $R_{s}$ is the equivalent resistance of the supercapacitor bank. Solving (8), the following equations can be obtained as:

$$
\begin{gathered}
I_{s}=\frac{D}{R_{s}} \cdot V_{d} \\
V_{s}=D V_{d}
\end{gathered}
$$

The state-space averaged ac model is expressed as:

$$
\frac{d}{d t}\left[\begin{array}{l}
\hat{i}_{s} \\
\hat{v}_{s}
\end{array}\right]=C \cdot\left[\begin{array}{l}
\hat{i}_{s} \\
\hat{v}_{s}
\end{array}\right]+D \cdot V_{d} \cdot \hat{d}
$$

where:

$$
C=\left[\begin{array}{cc}
0 & -\frac{1}{L_{s}} \\
\frac{1}{C_{s}} & -\frac{1}{C_{s} R_{s}}
\end{array}\right] \quad D=\left[\begin{array}{c}
\frac{1}{L_{s}} \\
0
\end{array}\right]
$$

where $\hat{d}$ is the small-signal duty ratio. Solving (11), the following equations can be obtained as:

$$
\begin{gathered}
\frac{\hat{v}_{s}}{\hat{d}}=\frac{\frac{\hat{i}_{s}}{C_{s}}}{s+\frac{1}{C_{s} R_{s}}} \cdot \frac{1}{\hat{d}} \\
\frac{\hat{i_{s}}}{\hat{d}}=\frac{V_{d}}{s L_{s}+\frac{1}{\frac{1}{R_{s}}+s C_{s}}}
\end{gathered}
$$




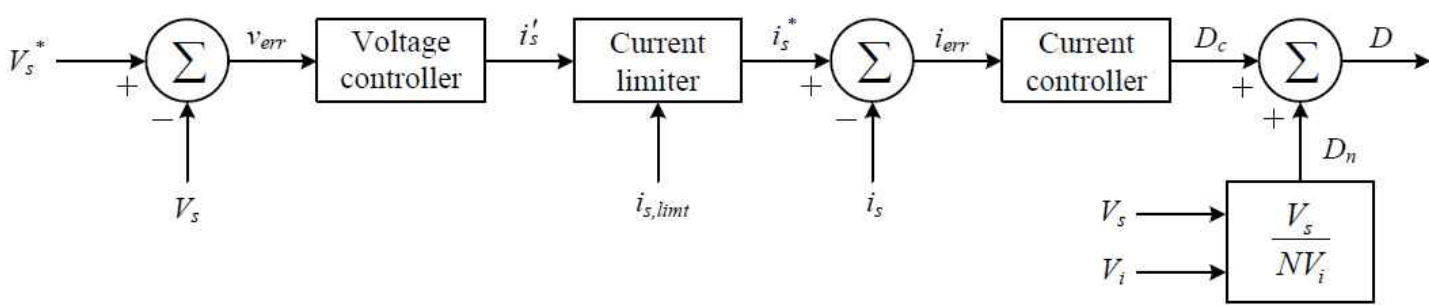

Fig. 7. Control block diagram of the supercapacitor charging controller.

\section{CONTROL StRATEgy}

Fig. 7 shows a control block diagram of the proposed converter. It is assumed that the output filter inductor current $i_{s}$ flows continuously. When $S_{1}$ and $S_{2}$ are turned on, the inductor current $i_{s}$ increases. The following voltage equation is obtained as:

$$
N V_{i}-L_{s} \frac{d i_{s}}{d t}-V_{s}=0 .
$$

On the other hand, when $S_{3}$ and $S_{4}$ are turned on, the inductor current $i_{s}$ freewheels through diode $D_{o 2}$. Then, the following voltage equation is obtained as:

$$
V_{s}-L_{s} \frac{d i_{s}}{d t}=0 .
$$

Depending on the duty cycle $D$ of $S_{1}$ and $S_{2}$, the average inductor voltage for $T_{s}$ gives the supercapacitor current variation $\Delta i_{s}$ as:

$$
\left(N V_{i}-V_{s}\right) D T_{s}-V_{s}(1-D) T_{s}=L_{s} \Delta i_{s} .
$$

By rearranging (14):

$$
N V_{i} D=V_{s}+L_{s} \frac{\Delta i_{s}}{T_{s}} .
$$

Here, the duty cycle $D$ is represented as:

$$
D=D_{n}+D_{c} \text {. }
$$

$D_{n}$ is a nominal duty cycle. $D_{c}$ is a controlled duty cycle. The nominal duty cycle $D_{n}$ and the controlled duty cycle $D_{c}$ can be represented as:

$$
\begin{gathered}
D_{n}=\frac{V_{s}}{N V_{i}} \\
D_{c}=L_{s} \frac{\Delta i_{s}}{N V_{i} T_{s}} .
\end{gathered}
$$

Then, the duty cycle $D$ becomes

$$
D=D_{n}+D_{c}=\frac{V_{s}}{N V_{i}}+L_{s} \frac{\Delta i_{s}}{N V_{i} T_{s}} .
$$

To force the supercapacitor current $i_{s}$ to track its current command $i_{s}{ }^{*}$, a proportional-integral (PI)-type current controller is used for the controlled duty cycle $D_{c}$ as:

$$
\begin{gathered}
D_{c}=k_{p} i_{\text {err }}+k_{i} \int i_{\text {err }} d t \\
i_{\text {err }}=i_{s}^{*}-i_{s} .
\end{gathered}
$$

The current error $i_{\text {err }}$ is calculated by comparing the current command $i_{s}{ }^{*}$ to the measured current $i_{s} . k_{p}$ and $k_{i}$ are the proportional and integral control gains, respectively. To regulate the supercapacitor voltage $V_{s}$, a PI-type voltage controller is used. The voltage error $v_{e r r}$ is calculated by comparing the reference supercapacitor voltage $V_{s}^{*}$ to the measured supercapacitor voltage $V_{s}$. The voltage controller generates the current command $i_{s}$. $i_{\text {s.limit }}$ is the maximum charging current of the supercapacitor. If $i_{s}$ is higher than $i_{\text {s.limit }}$, the supercapacitor is charged with a constant current. On the other hand, if $i_{s}^{\prime}$ is lower than $i_{\text {s.limit, }}$ the supercapacitor is charged with a constant voltage.

\section{EXPERIMENTAL RESULTS}

A $300 \mathrm{~W}$ prototype circuit has been built and tested to verify the operation principles and performance of the proposed converter. The input voltage ranges from $300 \mathrm{~V}$ to $400 \mathrm{~V}$. The supercapacitor voltage ranges from $30 \mathrm{~V}$ to $48 \mathrm{~V}$. Table II shows the values of the major circuit parameters. For the power switching devices, $S_{I}=S_{2}=S_{3}=S_{4}=$ FQA24N50C3 (Fairchild) and $D_{o 1}=D_{o 2}=$ DSEK6002A (IXYS) are used. The current stresses of the switching devices are different, as shown in Table I. The proposed converter adopts FQA24N50C3s for all of the four switches by considering the maximum current stresses of the switches. The FQA24N50C3 (24 A, $500 \mathrm{~V})$ can withstand the maximum allowable current stresses of all of the power switches. The power switches operate at a constant switching period of $20 \mu \mathrm{sec}$ with a dead time of $330 \mathrm{nsec}$. The transformer has a primary winding turns of $N_{p}=20$ and a secondary winding turns of $N_{s}=10$. The controller is digitally implemented by using a single-chip microcontroller dsPIC30F3011 (Mircochip).

The input voltage $V_{i}$, supercapacitor voltage $V_{s}$, and supercapacitor current $i_{s}$ are measured by voltage and current sensing amplifiers. They are sensed through the 10-bit A/D converter in the microcontroller. After the voltage and current signals are read, the duty cycle $D$ is obtained by calculating $D_{n}$ and $D_{c}$. Fig. 8 shows a picture of the hardware prototype including the proposed converter. The designed prototype system includes a power-factor correction circuit and the proposed dc-dc converter.

In order to verify the proposed converter operation and its 
TABLE II

MAIN CirCUIT PARAMETERS

\begin{tabular}{|c|c|}
\hline Circuit parameter & Value \\
\hline input voltage $V_{i}$ & $300 \mathrm{~V} \sim 400 \mathrm{~V}$ \\
\hline supercapacitor voltage $V_{s}$ & $30 \mathrm{~V} \sim 48 \mathrm{~V}$ \\
\hline switch output capacitor $C_{s}$ & $500 \mathrm{pF}$ \\
\hline clamping capacitor $C_{c}$ & $1 \mu \mathrm{F}$ \\
\hline transformer turns ratio $N$ & 0.36 \\
\hline magnetizing inductor $L_{m}$ & $250 \mu \mathrm{H}$ \\
\hline leakage inductor $L_{l k}$ & $4 \mu \mathrm{H}$ \\
\hline output filter inductor $L_{s}$ & $360 \mu \mathrm{H}$ \\
\hline
\end{tabular}

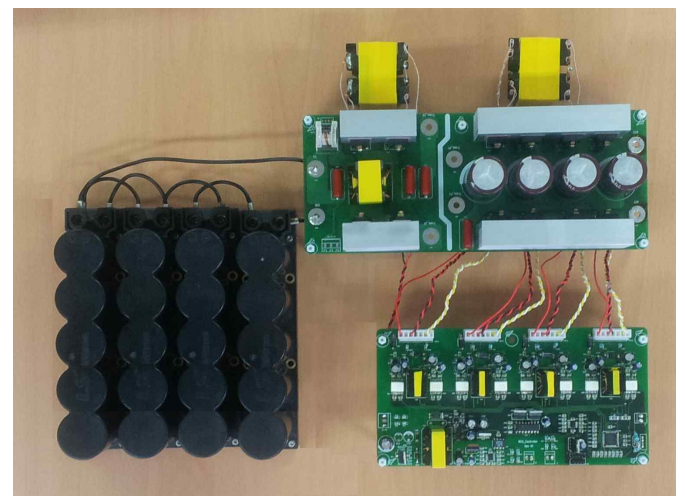

Fig. 8. Picture of the hardware prototype including the proposed converter.

control method, simulation results are presented in Fig. 9 through Fig. 11 by using PSIM 9.0 software. In the simulation, the control block is implemented by C-language-based DLL blocks. Fig. 9 shows the simulation waveforms when $D$ is 0.4 . Fig. 9(a) shows the primary current $i_{p}$ and switch voltages $V_{S 1}$ and $V_{S 4}$. Fig. 9(b) shows the primary current $i_{p}$ and switch voltages $V_{S 2}$ and $V_{S 3}$. Fig. 10 shows the simulation waveforms when $D$ is 0.6 . It is shown that the proposed converter can operate when the duty cycle is over 0.5 . It is also shown that all of the power switches are turned on at zero-voltage without any voltage spikes. Fig. 11 shows the simulation waveforms of the proposed converter for charging the supercapacitor banks. $C_{s}=$ $35-\mathrm{F}$ and $R_{s}=4.5 \mathrm{~m} \Omega$ are used for the supercapacitor bank parameters. As shown in Fig. 11, as the proposed converter supplies a constant current of $15 \mathrm{~A}$, the supercapacitor bank increases linearly. When the supercapacitor voltage reaches the maximum allowable voltage at $48 \mathrm{~V}$, the supercapacitor voltage is regulated constantly and the current decreases.

The conventional two-switch forward converter in [11] has been designed and tested for a performance comparison with the proposed converter. Fig. 12 shows the experimental waveforms of the conventional two-switch forward converter. It shows the primary current $i_{p}$ and switch voltages $V_{S I}$ and $V_{S 2}$

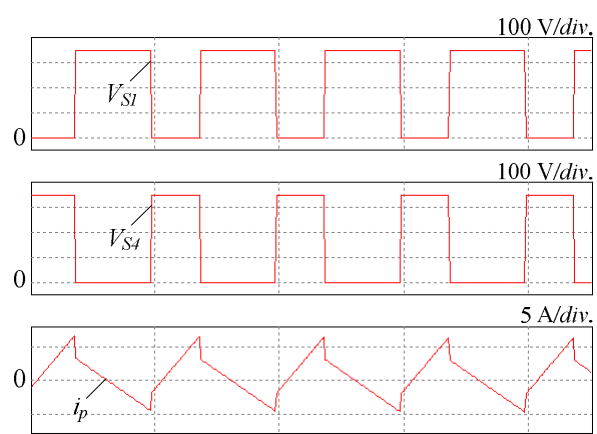

(a)

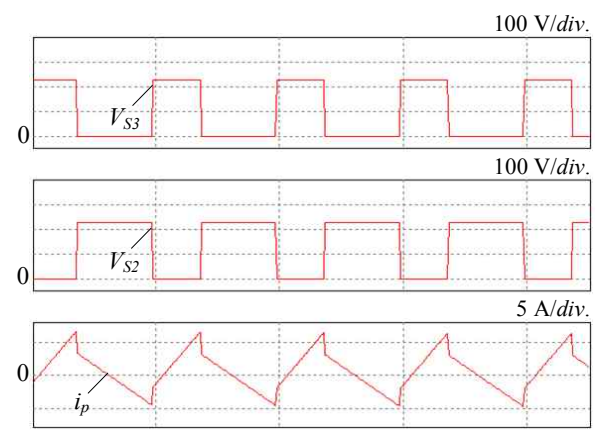

(b)

Fig. 9. Simulation results of the proposed converter when $D$ is 0.4 : (a) primary current $i_{p}$ and switch voltages $V_{S 1}$ and $V_{S 4}$ and (b) primary current $i_{p}$ and switch voltages $V_{S 2}$ and $V_{S 3}$.

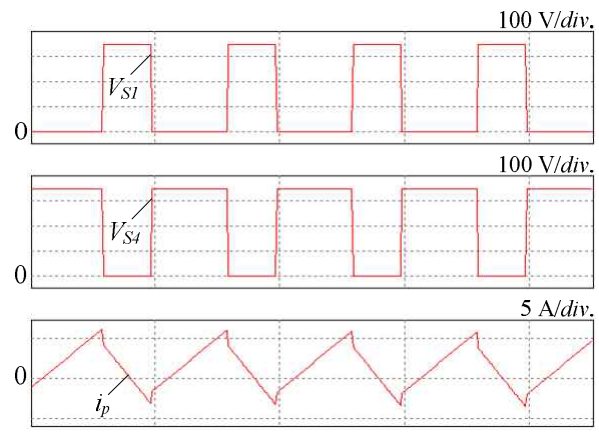

(a)
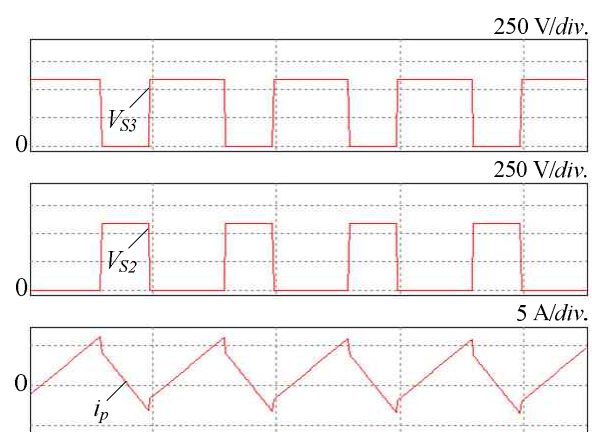

(b)

Fig. 10. Simulation results of the proposed converter when $D$ is 0.6: (a) primary current $i_{p}$ and switch voltages $V_{S l}$ and $V_{S 4}$ and (b) primary current $i_{p}$ and switch voltages $V_{S 2}$ and $V_{S 3}$. 


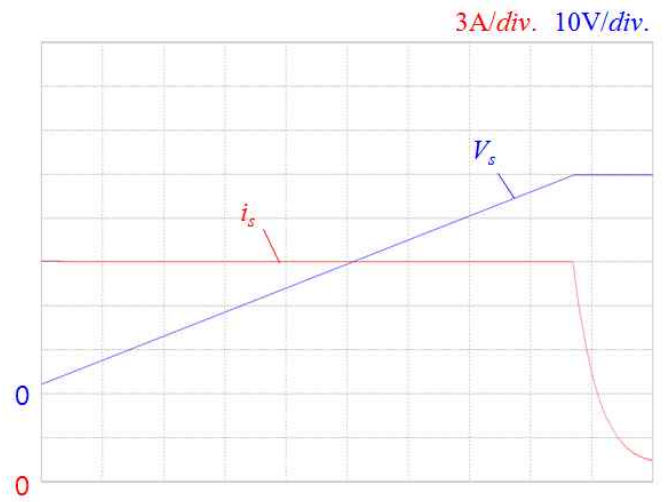

Fig. 11. Simulation waveforms of the proposed converter for charging the supercapacitor banks.

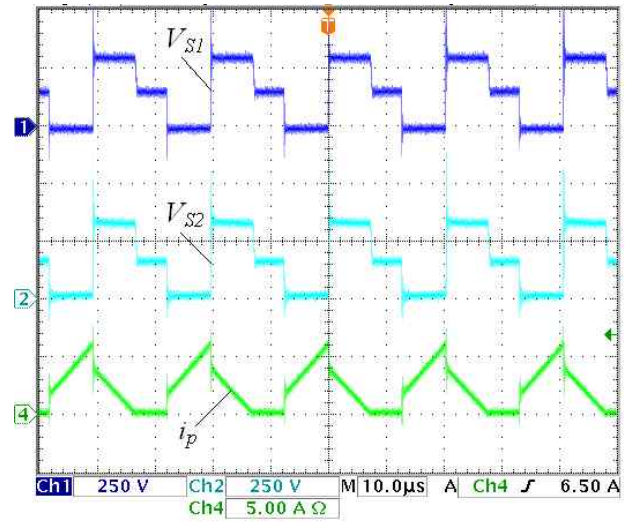

Fig. 12. Experimental waveforms of the conventional converter: primary current $i_{p}$ and switch voltages $V_{S I}$ and $V_{S 2}$.

of the conventional two-switch forward converter. When the switches are turned off, high voltage spikes are observed in Fig. 12. These voltage spikes increase the switching losses. Fig. 13 shows the experimental waveforms of the proposed converter when the duty cycle $D$ is 0.4 . Fig. 13(a) shows the primary current $i_{p}$ and switch voltages $V_{S I}$ and $V_{S 4}$. Fig. 13(b) shows the primary current $i_{p}$ and switch voltages $V_{S 2}$ and $V_{S 3}$. As shown in Fig. 13(a) and (b), when the switches are turned off, voltage spikes are not observed across the switches. Fig. 13(c) shows switch voltages $V_{S I}$ and $V_{S 2}$ and switch currents $i_{S l}$ and $i_{S 2}$. Fig. 13(d) shows switch voltages $V_{S 3}$ and $V_{S 4}$ and switch currents $i_{S 3}$ and $i_{S 4}$. As shown in Fig. 13(c) and (d), before the primary current $i_{p}$ changes its direction, the switch voltage is zero. Zero-voltage switching of the power switches is achieved, which significantly reduces the switching power losses.

Fig. 14 shows the experimental waveforms of the proposed converter when the duty cycle $D$ is 0.6 . Fig. 14(a) shows the primary current $i_{p}$ and switch voltages $V_{S I}$ and $V_{S 4}$. Fig. 14(b) shows the primary current $i_{p}$ and switch voltages $V_{S 2}$ and $V_{S 3}$. As shown in Fig. 14(a) and (b), zero-voltage switching of the power switches is achieved when the duty cycle $D$ is 0.6 . It can also be seen that the proposed converter can operate when the duty cycle is over 0.5 . Fig. 15 shows the experimental waveforms when the proposed converter charges the

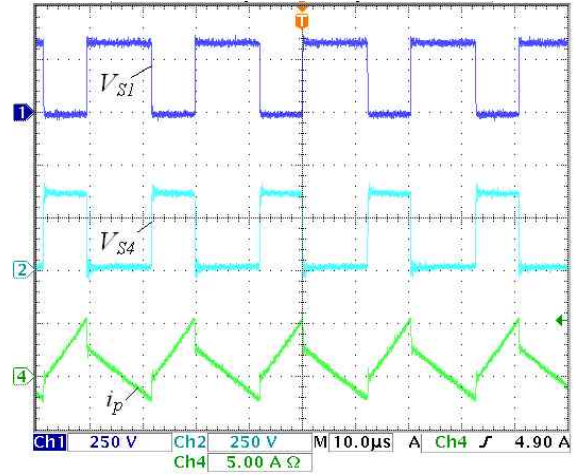

(a)

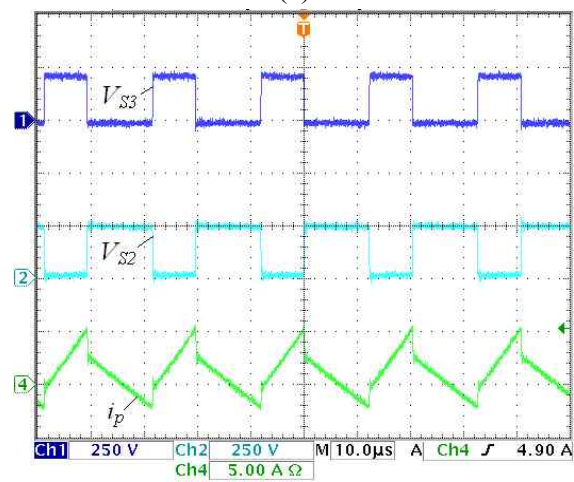

(b)

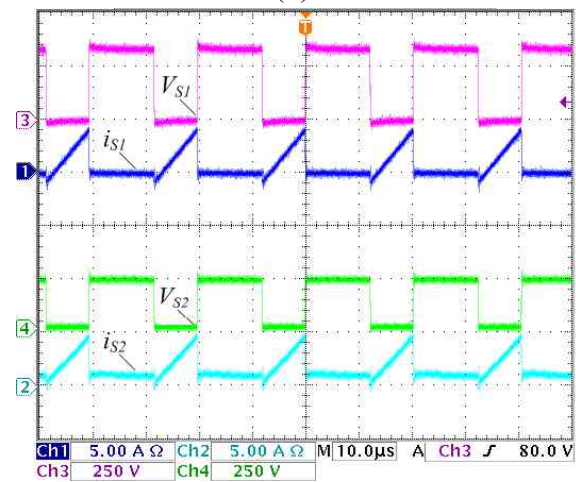

(c)

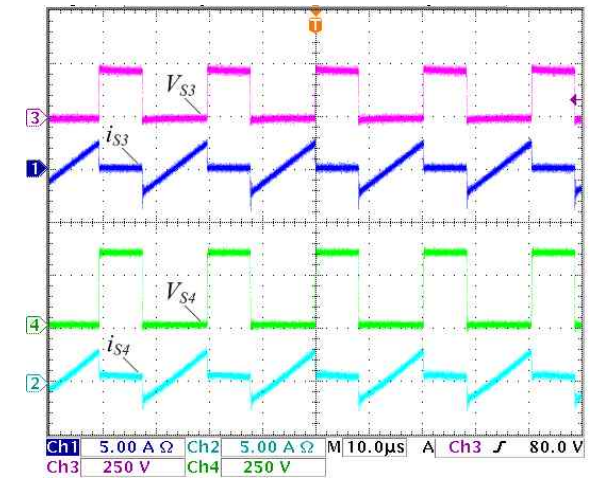

(d)

Fig. 13. Experimental waveforms of the proposed converter when $D$ is 0.4: (a) primary current $i_{p}$ and switch voltages $V_{S I}$ and $V_{S 4}$, (b) primary current $i_{p}$ and switch voltages $V_{S 2}$ and $V_{S 3}$, (c) switch voltages $V_{S 1}$ and $V_{S 2}$ and switch currents $i_{S 1}$ and $i_{S 2}$ and (d) switch voltages $V_{S 3}$ and $V_{S 4}$ and switch currents $i_{S 3}$ and $i_{S 4}$. 


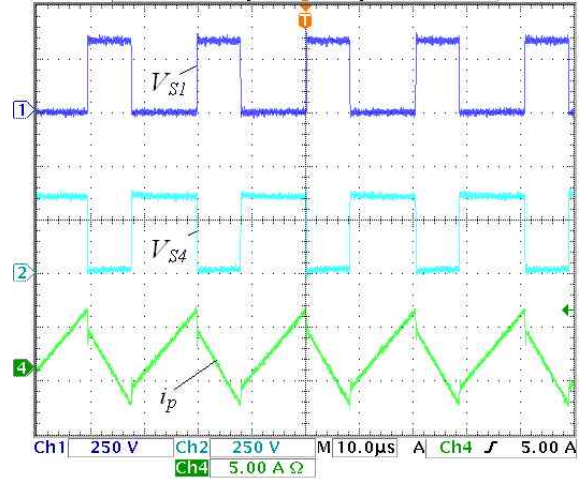

(a)

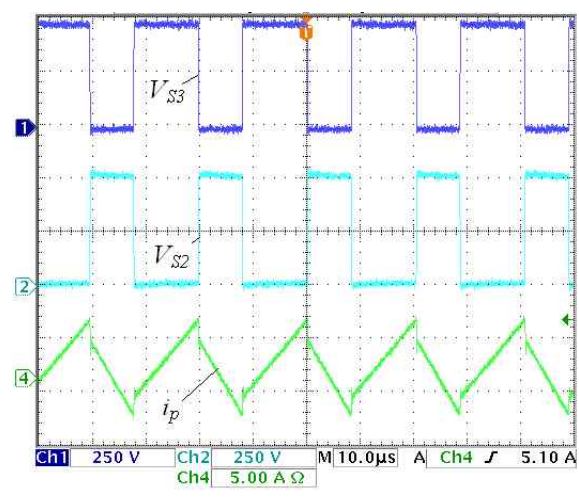

(b)

Fig. 14. Experimental waveforms of the proposed converter when $D$ is 0.6: (a) primary current $i_{p}$ and switch voltages $V_{S 1}$ and $V_{S 4}$ and (b) primary current $i_{p}$ and switch voltages $V_{S 2}$ and $V_{S 3}$.

supercapacitor bank. A supercapacitor bank is used, which consists of 20 supercapacitors connected in series. The rated capacitance per capacitor is $700 \mathrm{~F}$. Its rated voltage is $2.7 \mathrm{~V}$. Its equivalent resistance is $4.5 \mathrm{~m} \Omega$. The total equivalent resistance of the supercapacitor bank is $90 \mathrm{~m} \Omega$. As shown in Fig. 15, the proposed converter charges the supercapacitor bank by controlling the output filter inductor current $i_{s}$. The supercapacitor voltage increases from $35 \mathrm{~V}$ to $40 \mathrm{~V}$ linearly when the current command $i_{s}{ }^{*}$ is $3 \mathrm{~A}$.

Fig. 16 shows the experimental waveforms when the supercapacitor voltage $V_{s}$ reaches a maximum voltage of $48 \mathrm{~V}$. It also shows the supercapacitor voltage $V_{s}$ and the output filter inductor current $i_{s}$. The output filter inductor current $i_{s}$ flows continuously. Fig. 17 shows the dynamic response of the proposed converter when it charges the supercapacitor bank with a constant current of $15 \mathrm{~A}$. As the proposed converter supplies a constant current of $15 \mathrm{~A}$, the supercapacitor bank increases linearly. At the moment that the supercapacitor voltage reaches the maximum allowable voltage at $48 \mathrm{~V}$, the supercapacitor voltage is regulated constantly and the current decreases. In order to evaluate the efficiency, the conventional two-switch forward converter [11] and the proposed converter have been tested for the same power level. Fig. 18 shows the measured efficiencies of the converters for different power

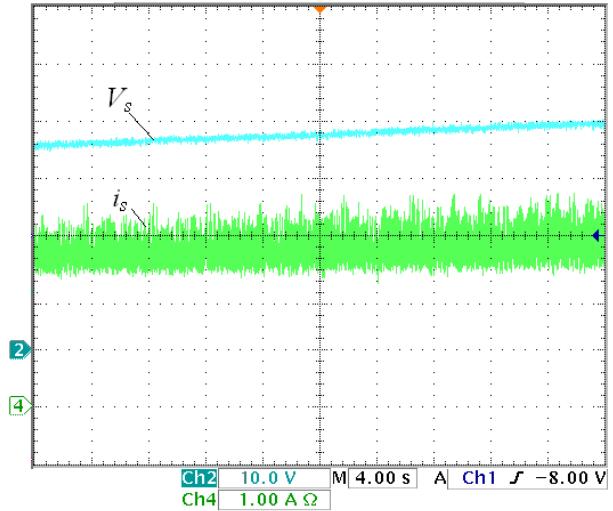

Fig. 15. Experimental waveforms of the proposed converter for charging the supercapacitor bank: supercapacitor voltage $V_{s}$ and output filter inductor current $i_{s}$.

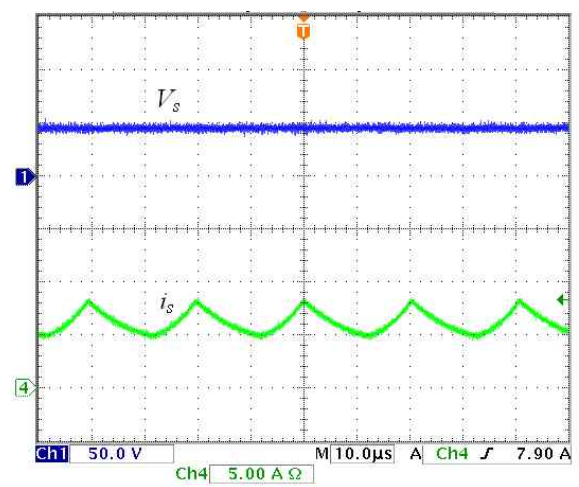

Fig. 16. Experimental waveforms of the proposed converter for charging the supercapacitor bank: supercapacitor voltage $V_{s}$ and output filter inductor current $i_{s}$.

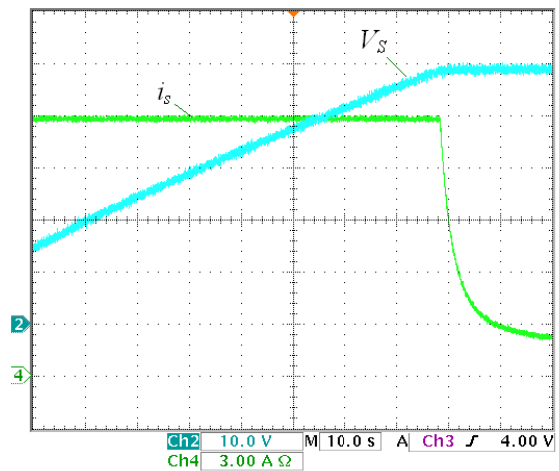

Fig. 17. Experimental waveforms of the proposed converter for charging the supercapacitor bank: supercapacitor voltage $V_{s}$ and output filter inductor current $i_{s}$.

levels. The conventional two-switch forward converter achieves an efficiency of $89 \%$ for $300 \mathrm{~W}$. On the other hand, the proposed converter achieves an efficiency of $93 \%$ for 300 W. The proposed converter improves the converter efficiency by $4 \%$ by achieving zero-voltage switching of the power switches. The duty cycle range is also extended for the use of the proposed converter at a high input voltage range of around

$300 \mathrm{~V}$ to $400 \mathrm{~V}$. In order to compare the efficiency of the 


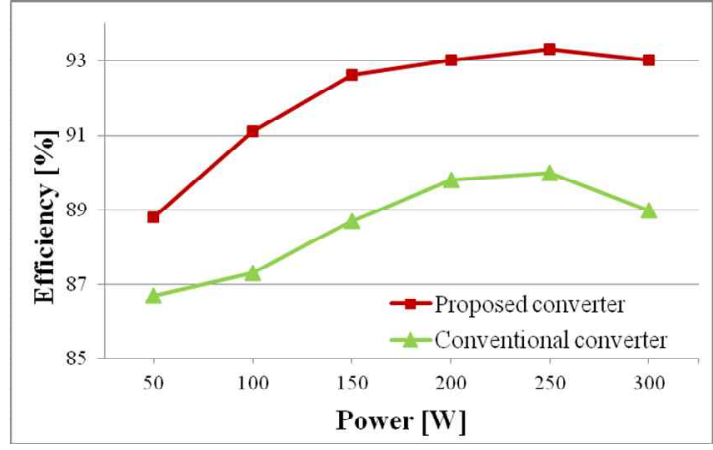

Fig. 18. Measured efficiencies for different power levels.

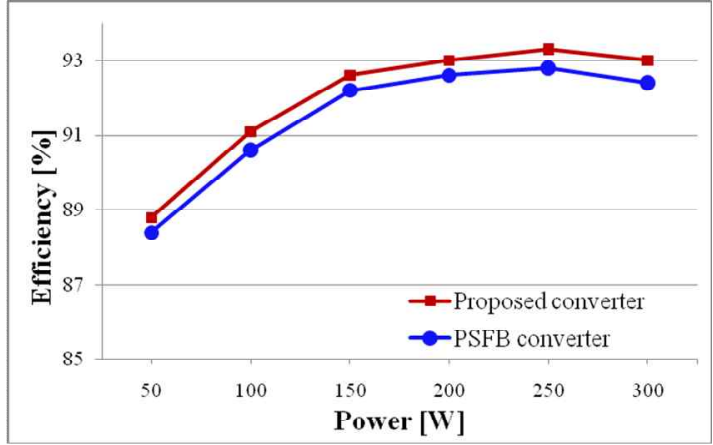

Fig. 19. Measured efficiencies for different power levels.

proposed converter with that of the PSFB converter [17], Fig. 19 shows the measured efficiencies of the converters for different power levels. The PSFB converter achieves an efficiency of $92.5 \%$ while the proposed converter achieves an efficiency of $93 \%$ for $300 \mathrm{~W}$. The proposed converter improves the converter efficiency by $0.5 \%$ by reducing the voltage stresses and by minimizing the circulating currents.

\section{CONCLUSIONS}

This paper proposed a high-efficiency two-switch forward converter for supercapacitor chargers. The proposed converter reduces switching losses with an extended duty cycle. The power switches are turned on at zero voltage without any voltage spikes. Zero-voltage switching of the power switches is achieved. The power efficiency is increased by reducing the switching losses. The proposed converter has the advantages of reduced switch voltage stresses and a minimized circulating current when compared to the other converter topologies. The supercapacitor charging strategy has been also presented by using a constant current and constant voltage charging control. All of the control functions are implemented in software with a single-chip microcontroller. The performance of the proposed converter has been verified through experimental results using a $300 \mathrm{~W}$ prototype circuit for a $54-\mathrm{V}$, 35-F supercapacitor bank. The proposed converter improves power efficiency by $4 \%$, from $89 \%$ to $93 \%$ at the rated power.

\section{ACKNOWLEDGEMENT}

This work was supported by the National Research Foundation of Korea (NRF) grant funded by the Korea government (MISP) (2010-0028509).

\section{REFERENCES}

[1] S. H. Kim, and W. J. Choi, "Selection criteria for supercapacitors based on performance evaluations," Journal of Power Electronics, Vol. 12, No. 1, pp. 223-231, Jan. 2012.

[2] M. Zandi, A. Payman, J.-P. Martin, S. Pierfederici, B. Davat, and F. Meibody-Tabar, "Energy management of a fuel cell/supercapacitor/battery power source for electric vehicular applications," IEEE Trans. Veh. Technol., Vol. 60, No. 2, pp. 433-443, Feb. 2011.

[3] S. Kim, and P. H. Chou, "Size and topology optimization for supercapacitor-based sub-watt energy harvesters," IEEE Trans. Power Electron., Vol. 28, No. 4, pp. 2068-2080, Apr. 2013.

[4] H. Gualous, H. Louahlia, and R. Gallay, "Supercapacitor characterization and thermal modelling with reversible and irreversible heat effect," IEEE Trans. Power Electron., Vol. 26, No. 11, pp. 3402-3409, Nov. 2011.

[5] T. S. Hwang, M. J. Tarca, and S. Y. Park, "Dynamic response analysis of DC-DC converter with supercapacitor for direct borohydride fuel cell power conditioning system," IEEE Trans. Power Electronics, Vol. 27, No. 8, pp. 3605-3615, Aug. 2012.

[6] S. Moisseev, S. Hamada, M. Ishitobi, E. Hiraki, and M. Nakaoka, "High-frequency forward transformer linked PWM DC-DC power converter with zero voltage switching and zero current switching bridge legs," Journal of Power Electronics, Vol. 2, No. 4, pp. 278-287, Oct. 2002.

[7] S. S. Lee, S. W. Choi, and G. W. Moon, "High efficiency active clamp forward converter with synchronous switch controlled ZVS operation," Journal of Power Electronics, Vol. 6, No. 2, pp. 131-138, Apr. 2006.

[8] L. D. Salazar and P. D. Ziogas, "A high-frequency two-switch forward converter with optimized performance," IEEE Trans. Industrial Electronics, Vol. 37, No. 6, pp. 496-505, Dec. 1990.

[9] Y. T. Jang, M. M. Jovanovic, and D. L. Dillman, "Soft-switched PFC boost rectifier with integrated ZVS two-switch forward converter," IEEE Trans. Power Electron., Vol. 21, No. 6, pp. 1600-1606, Nov. 2006.

[10] M. Prudik and P. Vorel, "Advantages of using two-switch forward converter for high-voltage applications," in Proc. SPEEDAM, pp. 326-330, 2012.

[11] P. Kong, S. Wang, F. C. Lee, and Z. Wang, "Reducing common-mode noise in two-switch forward converter," IEEE Trans. Power Electron., Vol. 26, No. 5, pp. 1522-1533, May 2011.

[12] L. D. Salazar, and P. D. Ziogas, "Design and evaluation of two types of controllers for a two-switch forward converter with extended duty cycle capability," IEEE Trans. Ind. Electron., Vol. 39, No. 2, pp. 128-140, Apr. 1992. 
[13] K. B. Park, G. W. Moon, and M. J. Yoon, "Two-switch active-clamp forward converter with one clamp diode and delayed turnoff gate signal," IEEE Trans. Ind. Electron., Vol. 58, No. 10, pp. 4768-4772, Oct. 2011.

[14] K. B. Park, C. E. Kim, G. W. Moon, and M. J. Yoon, "Three-switch active-clamp forward converter with low switch voltage stress and wide ZVS range for high-input-voltage applications," IEEE Trans. Power Electron., Vol. 25, No. 4, pp. 889-898, Apr. 2010.

[15] B. Y. Chen, and Y. S. Lai, "New digital-controlled technique for battery charger with constant current and voltage control without current feedback," IEEE Trans. Ind. Electron., Vol. 59, No. 3, pp. 1545-1553, Mar. 2012.

[16] K. Harada, and H. Sakamoto, "Non-resonant converter for megahertz switching," in Proc. PESC, pp. 889-894, 1989.

[17] R. Redl, N. O. Sokal, and L. Balogh, "A novel soft-switching full-bridge dc/dc converter: analysis, design considerations, and experimental results at $1.5 \mathrm{~kW}, 100$ kHz," IEEE Trans. Power Electron., Vol. 6, No. 3, pp. 408-418, Jul. 1991.

[18] C. Liu, A. Ridenour, and J. S. Lai, "Modeling and control of a novel six-leg three-phase high-power converter for low voltage fuel cell applications," IEEE Trans. Power Electron., Vol. 21, No. 5, pp. 1292-1300, Sep. 2006.

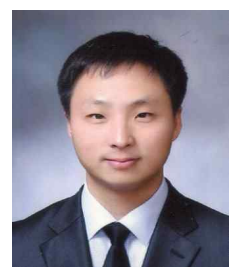

Woo-Young Choi was born in Gwangju, South Korea, in 1979. He received his B.S. in Electrical Engineering from Chonnam National University, Gwangju, South Korea, in 2004, and his Ph.D. in Electronic and Electrical Engineering from the Pohang University of Science and Technology (POSTECH), Pohang, South Korea, in 2009.

Since 2010, he has been with the Division of Electronic Engineering at Chonbuk National University, Jeonju, South Korea, where is currently working as an Assistant Professor. His current research interests include power electronics and control for high-efficiency switching power converter designs.

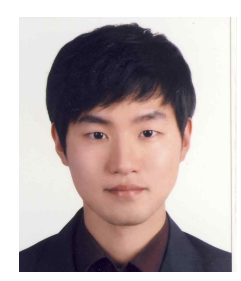

Min-Kwon Yang was born in Jeonju, South Korea, in 1987. He received his B.S. in Electronic Engineering from Chonbuk National University, Jeonju, South Korea, in 2012. He is currently working toward his Ph.D. in Electronic Engineering at Chonbuk Nation University.

His current research interests include digital power converters for high efficiency and renewable energies.

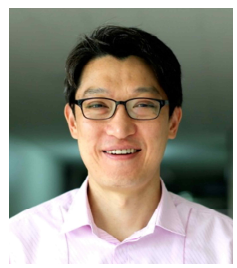

Yongsug Suh was born in Seoul, South Korea. He received his B.S. and M.S. in Electrical Engineering from Yonsei University, Seoul, South Korea, in 1991 and 1993, respectively, and his Ph.D. in Electrical Engineering from the University of Wisconsin, Madison, WI, USA, in 2004. From 1993 to 1998, he was an Application Engineer in the Power Semiconductor Division of Samsung Electronics Co. From 2004 to 2008, he was a Senior Engineer in the Power Electronics and Medium Voltage Drives Division of ABB, Turgi, Switzerland. Since 2008, he has been with the Department of Electrical Engineering, Chonbuk National University, Jeonju, South Korea, where he is currently an Associate Professor. His current research interests include the power conversion systems of high power for renewable energy sources and medium voltage electric drive systems. 